\title{
Is a Microsatellite Instability Still Useful for Tailored Treatment in Stage II and III Colon Cancer?
}

\author{
Nam Kyu Kim \\ Department of Surgery, Yonsei University College of Medicine, Seoul, Korea
}

\section{See Article on Page 28-34}

Colorectal cancer (CRC) is a heterogeneous tumor in terms of different types of genetic instabilities and molecular pathogeneses. Through a molecular analysis, CRC can be classified into several groups based on genomic status (microsatellite instability and chromosomal instability) and epigenomic status (CpG island methylator phenotype) [1]. These molecular characteristics are usually more useful than histopathologic features in not only establishing the pathogenesis of a particular colon cancer but also predicting patient prognosis. A microsatellite instability (MSI) is a phenomenon that occurs in a subset of CRC (15\%-20\%) and manifests itself as an expansion or a deletion of a microsatellite repeat in the patient's tumor DNA, when compared to the patient's normal DNA. The DNA mismatch repair (MMR) gene normally corrects replicative errors. The DNA MMR system consists of several proteins, such as MLH1, MSH2, MSH6, and PMS2, which detect and correct these errors. A defective DNA MMR and subsequent MSI result either from a MMR gene germline or somatic mutation or from methylation of a MMR promoter gene (usually MLH1), resulting in the loss of protein function.

A MSI is generally due to a defective MMR. A defective MMR is found in most of the patients with clinically-diagnosed hereditary nonpolyposis colorectal cancer (HNPCC) and in approximately $13 \%-20 \%$ of those diagnosed with sporadic CRC. MSI-H cancers generally show a more favorable prognosis than MSS/MSS-L cancers [2]. Cancers with or without instability at $<40 \%$ of tested loci are defined as MSS and MSI-L cancer, respectively. On the other hand, MSI-H cancers defined as high degree of microsatellite in-

Correspondence to: Nam Kyu Kim, M.D.

Department of Surgery, Yonsei University College of Medicine, 50 Yonsei-ro, Seodaemun-gu, Seoul 120-749, Korea

Tel: +82-2-2228-2117, Fax: +82-2-313-8289

E-mail:namkyuk@yuhs.ac

(c) 2014 The Korean Society of Coloproctology

This is an open-access article distributed under the terms of the Creative Commons Attribution NonCommercial License (http://creativecommons.org/licenses/by-nc/3.0) which permits unrestricted noncommercial use, distribution, and reproduction in any medium, provided the original work is properly cited. stability at $>40 \%$ [3]. A meta-analysis of CRC patients including 1,277 MSI-H patients showed that MSI-H cancers were associated with a better prognosis than MSS cancers [4]. In addition, MSI-H cancers have a lower incidence of lymph-node or systemic metastasis compared to MSS cancers. Furthermore, adjuvant 5-Fluorouracil systemic chemotherapy has been revealed to have no oncologic benefits in the treatment of stages II and III colon cancer [5]. This study analyzed retrospectively the clinicopathologic features and prognoses in patients with stages II and III MSI CRCs [6]. Surprisingly, current study showed that stage II MSI-H CRC had a significantly unfavorable trend for 3-year disease free survival compared to MSI-L/MSS CRC, even though the study demonstrated that the clinicopathologic features in MSI-H cancer were similar to those reported in other studies. Furthermore, interestingly, the MSI-H phenotype was a significantly independent poor prognostic factor in the multivariate analysis.

A previous study had demonstrated that fluorouracil and leucovorin (FL) adjuvant chemotherapy was associated with a good prognosis for patients with stage II and stage II MSI colorectal cancers [7] while another study, in contrast, reported conflicting outcomes [8]. This study included only $20 \mathrm{MSI}-\mathrm{H}$ patients, which number of patients seems to be too small to evaluate any effect of FL adjuvant therapy in stage II MSI-H patients. These observations indicate that MSI status still remains controversial in terms of predicting outcomes and personalized therapy. Although the benefit of adjuvant chemotherapy has been well established in patients with stage III CRC, whether FL adjuvant therapy is effective for treating for stage II MSI CRC is still not clear. Therefore, studies with larger numbers of high-risk stage II patients are necessary to accurately evaluate the true benefit of adjuvant therapy. Until these issues are addressed, concluding that MSI-H patients with stage II cancer do not benefit from FL adjuvant therapy may be premature. However, MMR status may be especially useful in the identification of patients who have Lynch syndrome and may influence the decision as to the need for further adjuvant treatment of CRC patients. 


\section{REFERENCES}

1. Grady WM, Carethers JM. Genomic and epigenetic instability in colorectal cancer pathogenesis. Gastroenterology 2008;135:107999.

2. Guastadisegni C, Colafranceschi M, Ottini L, Dogliotti E. Microsatellite instability as a marker of prognosis and response to therapy: a meta-analysis of colorectal cancer survival data. Eur J Cancer 2010;46:2788-98.

3. Popat S1, Hubner R, Houlston RS. Systematic review of microsatellite instability and colorectal cancer prognosis. J Clin Oncol 2005;23:609-18.

4. Hong SP, Min BS, Kim TI, Cheon JH, Kim NK, Kim H, et al. The differential impact of microsatellite instability as a marker of prognosis and tumour response between colon cancer and rectal cancer. Eur J Cancer 2012;48:1235-43.

5. Shin US, Cho SS, Moon SM, Park SH, Jee SH, Jung EJ, et al. Is microsatellite instability really a good prognostic factor of colorectal cancer? Ann Coloproctol 2014;30:28-34.

6. Watanabe T, Wu TT, Catalano PJ, Ueki T, Satriano R, Haller DG, et al. Molecular predictors of survival after adjuvant chemotherapy for colon cancer. N Engl J Med 2001;344:1196-206.

7. Ribic CM, Sargent DJ, Moore MJ, Thibodeau SN, French AJ, Goldberg RM, et al. Tumor microsatellite-instability status as a predictor of benefit from fluorouracil-based adjuvant chemotherapy for colon cancer. N Engl J Med 2003;349:247-57. 